\title{
An Assessment of Final-Year Medical Students and Interns Awareness of Radiation Exposure to Common Diagnostic Imaging Procedures
}

\author{
Seife Teferi Dellie, Daniel Admassie, and Yenework Ewnetu \\ Department of Radiology, College of Health Sciences, Addis Ababa University, Ethiopia \\ Correspondence should be addressed to Seife Teferi Dellie; seifeteferi@yahoo.com
}

Received 4 February 2014; Revised 9 June 2014; Accepted 2 July 2014; Published 24 July 2014

Academic Editor: Zsolt Szücs-Farkas

Copyright (C) 2014 Seife Teferi Dellie et al. This is an open access article distributed under the Creative Commons Attribution License, which permits unrestricted use, distribution, and reproduction in any medium, provided the original work is properly cited.

\begin{abstract}
Objectives. To evaluate the level of knowledge about the radiation exposure to diagnostic imaging procedures among the final-year medical students and interns and to suggest how education could be improved. Material and Methods. All 355 final-year medical students and interns from Tikur Anbessa Teaching Hospital in Addis Ababa were included in the study. Participants were asked to complete a questionnaire consisting of their actual knowledge on ionizing radiation and on their preferred method of learning. All questions were in multiple choice formats ranging from 4 to 7 choices. The obtained data were analyzed using statistical software. Results. A total of 343 completed questionnaires were received. Up to $78.9 \%$ of respondents underestimated or do not know the radiation dose from commonly requested radiological procedures. Surprisingly, 245 (71.4\%) and 254 (79.3\%) students incorrectly believed that ultrasound and MRI, respectively, emit ionizing radiation or they do not know if they emit radiation or not. Both interns and medical students did not have significant difference $(P=0.56)$ in their knowledge of ionizing radiation. A combination of tutorials or workshops (29.7\%) and learning modules (19.8\%) combined were their first and last preferred methods of teaching for future radiation awareness, respectively. Conclusion. This study has clearly shown that awareness of ionizing radiation from diagnostic imaging is lacking among senior medical students and interns. The results highlight the need for improved education to minimize unnecessary exposure of patients.
\end{abstract}

\section{Introduction}

Nowadays, medical imaging procedures involving the use of ionizing radiation are used daily in hospitals and clinics, making possible more accurate diagnosis of diseases and injuries. However, the use of ionizing radiation such as X-rays is also associated with potentially harmful biological effects specifically; high radiation doses tend to kill cells, while low doses tend to damage or alter the DNA of irradiated cells $[1,2]$.

The risk of radiation exposure from medical imaging is not insignificant; it is now believed that a linear relationship exists between radiation exposure and cancer development. In recent times, many studies have clearly documented the harmful effects of radiation exposure [3-7]. Evidences suggest that exposure of fetus in utero during pregnancy may lead to wide range of malformations. Early childhood (up to
10 years) exposure carries an enhanced radiation risk, and it has been estimated that the probability of induction of cancer especially leukaemia is about two to three times higher than adults [7]. This may be due to pediatric patients smaller body size relative to adults, rapid cellular growth, and after exposure longer period of survival life compared to adults. A British survey in 1989 showed that $4 \%$ of all CT examinations were performed for children younger than 15 years of age [8]; however, by 1999 , this figure had risen up to $11.2 \%$ [9].

In addition, there is a concern that $\mathrm{CT}$ parameters are not always adjusted to take into account the age and varying sizes of pediatric patients $[10,11]$ with children being frequently imaged using adult CT protocols [12], thus exposing them to an unnecessary high radiation dose as a consequence.

Many studies indicate that primary care providers are unaware of the hazards associated with the use of radiation. 
Physicians who are responsible for requesting radiological examinations tend to underestimate the actual doses involved, have poor knowledge about the possible risks to the health of populations, and do not discuss the potential risks of CT scans with their patients [13-20].

In a research done in Pakistan, the majority of medical students have limited knowledge about various aspects of radiation sources, the risk involved, and protection [21]. Similarly, in a research done in Australia among interns and senior medical students, there was clear lack of awareness about ionizing radiation doses from commonly requested diagnostic procedures [22]. Another research done in Australia among doctors working in the emergency department assessed emergency doctors' knowledge of radiation exposure for medical imaging and it was found to be poor, and whether they would inform their patients of the risks of radiation exposure varied with the clinical scenario. Overall, these doctors underestimated radiation exposure of frequently used diagnostic imaging and the associated risks. Underestimation of doses and risks may lead to doctors requesting more diagnostic imaging than they would if they had accurate knowledge [23].

In a survey done in Northern Ireland among health professionals on awareness of radiation dose, it was confirmed that clinician awareness of radiation doses imparted during common radiological procedures and the consequent risk to the individual patient is poor.

It was identified that radiological courses do increase awareness about radiation dose. There is a need to educate clinicians about ionizing radiation relevant to medical imaging and their clinical role to provide accurate information to their patients [20].

Many universities in Africa have medical schools that offer training and give a degree in medicine. However, there are only few which give radiology course for their students during their undergraduate studies. This is striking, since, after graduation, these physicians will be the only health professionals having the authority to request radiological examinations. In addition, there is a lack of studies in Ethiopia about the hazards of unnecessary use of radiological examinations. There is only one study among medical doctors on the knowledge and awareness of radiation exposure during common radiological procedures; the result was poor [24]. Therefore, the aim of this study was to evaluate awareness of radiation doses from commonly requested radiological procedures among senior medical students and interns at Tikur Anbessa Specialized General Hospital.

\section{Materials and Methods}

A hospital-based cross-sectional study was conducted in Addis Ababa University, College of Health Science, Addis Ababa, where there are medical students from the first year to the final year including their internship program. The study period was from April 1, 2013 to April 30, 2013. All final-year medical students and interns of AAU in the year 2013 were included in the study. All of them have their residence in the compound of Tikur Anbessa Specialized
Hospital. Tikur Anbessa Specialized Hospital is the biggest in the country and is the only territory under the administration of the university, and students and interns will have clinical attachment in this hospital. They have four groups each with different clinical attachment, they have one coordinator, and they were approached by the help of their coordinators.

Brief and easily understandable questionnaires were prepared. They consist of 5 questions on the participant's demographics and perceived understanding and importance of radiation knowledge, 16 questions testing their actual knowledge on ionizing radiation doses, and 2 questions on their preferred method of learning for future education on the subject; all questions are in multiple choice formats ranging from 4 to 7 choices. Data was analyzed using SPSS for Windows version 15.0 for calculating means and cross tabulation. Comparisons of mean were performed using Student's $t$-test. Level of statistical significance was set at $P<0.05$.

The study was first approved by the Ethical Review Committee of Addis Ababa University. Information sheet explaining the objectives of the study and the benefit of the research findings was provided to each study subject before submitting the questionnaire. Before collecting the data, individuals were asked for willingness to be included in the study and the purpose of the study was thoroughly explained to them. An informed verbal consent was obtained from each individual involved in the research.

\section{Result}

Out of the 355 questionnaires distributed, 350 questionnaires were returned, and of these, 343 had completed answers (98\% response rate). One hundred fourteen (33.2\%) were interns and $229(66.8 \%)$ were final-year medical students. A hundred (29.1\%) of them were divided as follows: 90 (26.2\%) thought that they were at least moderately confident and $10(2.9 \%)$ thought that they were very confident in their knowledge of ionizing radiation doses, while $51(14.9 \%)$ of them were divided as follows: 14 (4.1\%) believed that knowledge of radiation was "not really important," $1(0.3 \%)$ believed that it is "not important at all," and 36 (10.5\%) "do not know if it is important or not." A score was given to each respondent; this was calculated as a percentage of the number of correctly answered questions related to knowledge of ionizing radiation. The percentages of participants, who correctly identified, underestimated or said they do not know, and overestimated doses for common radiological investigations, are shown in Table 1 . The overall result is summarized in Figure 1. The radiation dose from a standard chest X-ray was correctly identified by only $47(13.7 \%)$ respondents. Of note, $245(71.4 \%)$ and $254(79.3 \%)$ incorrectly believed that ultrasound and MRI, respectively, emit ionizing radiation or they do not know if they emit radiation or not. Up to $296(86.3 \%)$ underestimated or do not know the risk of fatal cancer from an abdominal CT scan.

Knowledge of organ sensitivities to ionizing radiation was not also encouraging as expected with only 150 (43.7\%) correctly identifying the gonads as the most sensitive organs. 
TABLE 1: Percentages of participants correctly identifying, underestimating or saying that they do not know, and overestimating ionizing radiation doses from 9 commonly requested radiological investigations.

\begin{tabular}{lccc}
\hline Questions & $\begin{array}{c}\text { \% of the } \\
\text { underestimating } \\
\text { participants or } \\
\text { those who DN (do } \\
\text { not know) }\end{array}$ & $\begin{array}{c}\text { \% of the } \\
\text { correctly } \\
\text { identifying } \\
\text { participants }\end{array}$ & $\begin{array}{c}\text { \% of the } \\
\text { overestimat- } \\
\text { ing } \\
\text { participants }\end{array}$ \\
\hline Background & 71.2 & 19.2 & 9.6 \\
radiation & 69.1 & 13.7 & 17.2 \\
Chest X-ray & 65 & 16.3 & 18.7 \\
Ankle X-ray & 86.7 & 10.8 & 2.6 \\
Abdominal X-ray & 62.4 & 1.5 & 36.1 \\
Abdominal US & 94.7 & 3.8 & 1.5 \\
Abdominal CT & 95.9 & 4.1 & 0 \\
Barium meal & 98.6 & 1.5 & 0 \\
Spine MRI & 56 & 20.7 & 23.3 \\
Bone scan & 40.2 & 4.4 & 22.7 \\
PET scan & 86.3 & 8.5 & 5.2 \\
Fatal cancer (CT) & & &
\end{tabular}

The mean scores of subgroups according to year of medical school or internship, age, confidence, and perceived importance of radiation knowledge were compared (Table 2). The mean for interns (mean score 1.0) did not have significant difference when compared with final-year medical students groups (mean score 1.4). The mean of those between the age of 25 and the age of 29 (mean score 3.9) was higher than that of those between the age of 20 and the age of 24 (mean score 2). Those who perceived that radiation knowledge was moderately important or very important achieved higher mean scores (5.2) than those who thought that such knowledge was "not really important" or "not important at all" (2.8). With regard to the participants' confidence of their radiation knowledge, those who were "very confident" or "moderately confident" achieved higher mean scores (8.2) compared with those who were "not really confident" or had "no idea" (mean score 3.6).

In terms of radiation awareness, $34.8 \%$ of respondents acknowledged that they had some form of education on ionizing radiation previously in the form of lectures (21.3\%), tutorials/workshops (7.3\%), or a combination of these $5.2 \%$. A breakdown of the preferred types of education for each subgroup is shown in Figure 2. If the respondents were to have a choice in the format of education for further radiation awareness, they answered that a combination of tutorials or workshops (29.7\%) and learning modules (19.8\%) would be their first and last choices, respectively.

\section{Discussion}

Everyone alive in this world is being exposed to ionizing radiations. The risk of ionizing radiation from medical imaging is not insignificant. It is now believed that a linear
TABLE 2: The mean scores of subgroups according to year of medical school or internship, age, confidence, and perceived importance of knowledge of radiation.

\begin{tabular}{lcc}
\hline & Subgroups & Mean score \\
\hline Year of study & Medical students & 1.48 \\
& Interns & 1.0 \\
\hline \multirow{2}{*}{ Age } & $20-24$ & 2 \\
& $25-29$ & 3.9 \\
& $30-34$ & 5 \\
Confidence with & $35+$ & None \\
knowledge & Very confident & 4.7 \\
& Noterately confident & 3.4 \\
& No idea & 2.2 \\
Perceived & Very important & 1.4 \\
importance & Moderately important & 2.8 \\
& Not really important & 2.4 \\
& Not important at all & 0.58 \\
\hline
\end{tabular}

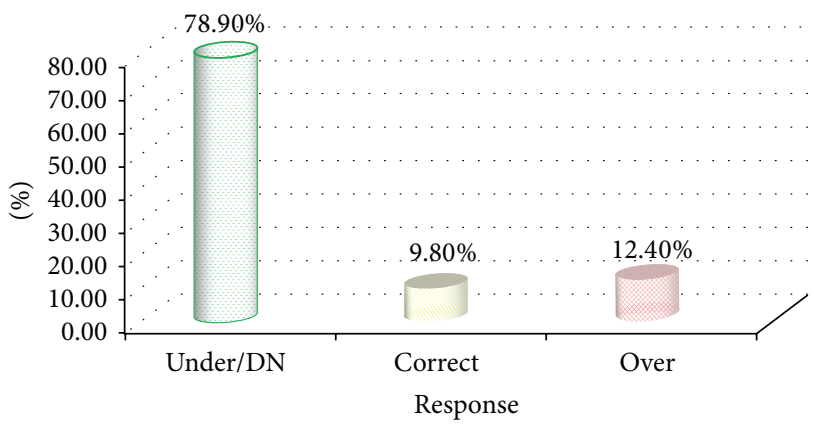

FIGURE 1: Summary of overall result of final-year medical students and interns in Tikur Anbessa Hospital during the study period. DN $=$ do not know.

relationship exists between radiation exposure and cancer development.

Although the absolute risk to an individual may be small, exposure of large numbers of people over time and repeated exposure of individual patients may lead to a significant increase in cancer cases. Furthermore, it is believed that up to a third of all requested radiological studies are completely or partially unnecessary $[6,21]$. The use of alternative medical imaging techniques using less radiation should be considered when clinical decisions are being made.

Medical students and internes represent future medical practitioners. Unless they are taught which imaging methods use radiation and the approximate quantity of radiation involved, they will be unable to make appropriate informed clinical decisions. It is the responsibility of referring doctors to assess the risks and benefits of any investigations or procedures requested in the management of a patient. Radiological tests are no exception. However, there is increasing concern in the literature that there is limited appreciation of radiation doses from diagnostic imaging by referring doctor. This 


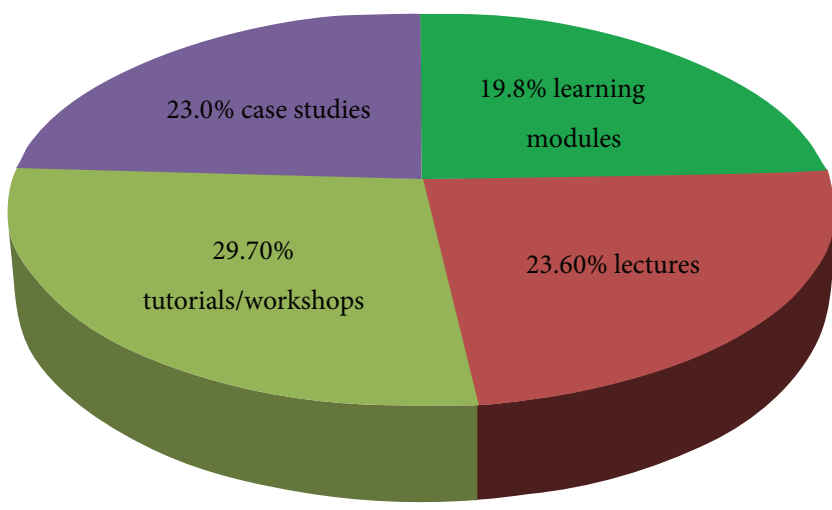

FIgURE 2: Preferred method of education by final-year medical students and interns in Tikur Anbessa Hospital during the study period.

lack of knowledge makes it difficult for doctors to inform patients about the risks and benefits of a radiological test. Furthermore, there is also the danger of underestimating the risks of imaging-related radiation, leading to unnecessary exposure of individual patients and the community.

In our sample, the mean score for interns $1.0(6.25 \%)$ and that of final-year medical students $1.4(8.75 \%)$ are significantly lower when compared with a similar study done among interns and final-year medical students in Australia whose mean score was $6(31.6 \%)$ [22]; the explanation could be that the percentage of participants in Australia who had previous education on ionizing radiation was significantly higher $(78.2 \%)$ when compared to our study where only $34.8 \%$ of participants had previous forms of education.

Awareness did not increase with seniority; there was no significant difference between interns and medical students $(P=0.56)$. It is alarming that $14.9 \%$ of participants believed that such knowledge was either "not really important" or "not important at all" or "they do not know if it is important or not." This group scored significantly lower than those who believed that radiation knowledge was "moderately important" or "very important" $(P=0.002)$. These findings are similar to that of the research done in Australia.

Surprisingly, 245 (71.4\%) and 254 (79.3\%) incorrectly believed that ultrasound and MRI, respectively, emit ionizing radiation or they do not know if they emit radiation or not. This finding is significantly higher when compared with previous similar study in Australia reporting the percentage of respondents who do not know that ultrasound does not emit ionizing radiation to be $11.3 \%$ and for MRI to be $25.5 \%$ [8]. Similar explanation could be given for this significant difference with the previous study in Australia; the number of participants who had previous education on ionizing radiation is less in our study. This is of concern as such doctors would not therefore be aware of safer alternatives to investigate their patients.

Education is ultimately the only way to increase awareness of the potential risks of ionizing radiation. Yet despite having some form of education on this subject previously, participants scored poorly. In our study also those between the age groups of 25 and 29 scored higher than those between
20 and $24(P=0.001)$; this difference may be due to practical experience because of their age variations.

The results of this research emphasize the need for further education of present and future doctors. While previous education obtained was primarily in the form of lectures, participants showed equal preferences for lectures and case studies for further education. Although further studies will be required to optimize the modality of education and clinical relevance, action should be taken urgently to protect the patient population in the future from such unnecessary radiation.

The results of our study clearly highlight the lack of awareness of ionizing radiation doses from commonly requested radiological procedures among senior medical students and interns in Ethiopia. There is a need to further educate current and future referring doctors in order to minimize unnecessary exposure of individual patients and the community to radiation and its accompanying risk of cancer. Due to the limitation of resources, this research deals only with Tikur Anbessa Specialized Hospital. Further studies are required to determine the optimum method of improving awareness. It is also a good start that AAU, College of Medicine has incorporated radiology attachment for final-year medical students; through this time the Department of Radiology should include topics which could raise the level of radiation awareness for the students. Radiation doses and associated risks should also be provided on imaging request forms. This would allow the requesting doctors, as the subjects of this study are future doctors of the country, to consider this information and discuss the risks with patients. This may increase doctors' general awareness and have a more lasting effect on overall knowledge and behavior.

\section{Appendix}

\section{Questionnaire}

Please circle the appropriate answer

Personal questions DN $=$ Do not know

(1) Which one describes you best?

(A) Senior medical student

(B) Intern doctor

(2) Which age do you belong to?
(A) $20-24$
(B) $25-30$
(C) 31-35
(D) Greater than 35

(3) Sex:
(A) Female
(B) Male 
(4) How confident are you in your knowledge of ionizing radiation dose of common radiological investigation?
(A) Very confident
(B) Moderately confident
(C) Not really confident
(D) Do not have any idea about ionizing radiation

(5) How important do you think is the need of knowledge of ionizing radiation dose of common radiological investigation in medical practice?
(A) Very important
(B) Moderately important
(C) Not really important
(D) Not important at all
(E) $\mathrm{DN}$

Questions related to diagnostic imaging (The SI unit of ionizing radiation is Sieverts, Sv)

(6) How much radiation in mili Sieverts, $\mathrm{mSv}$, is a person exposed to, on average, every year, from natural background radiation?
(A) 0.24
(B) 2.4
(C) 24
(D) 240
(E) $\mathrm{DN}$

(7) What is the approximate radiation dose, in $\mathrm{mSv}$, on chest X-ray?
(A) 0.02
(B) 0.2
(C) 2
(D) 20
(E) $\mathrm{DN}$

What is the dose in chest X-ray equivalents for the following radiological investigations?

(8) Ankle X-ray
(A) 0
(B) $1-5 \mathrm{X}$
(C) $5-10 \mathrm{X}$
(D) $10-50 \mathrm{X}$
(E) 50-300X
(F) Greater than 300X
(G) DN

(9) Abdominal X-ray
(A) 0
(B) $1-5 \mathrm{X}$
(C) $5-10 \mathrm{X}$
(D) $10-50 \mathrm{X}$
(E) $50-300 \mathrm{X}$
(F) Greater than 300X
(G) DN

(10) Abdominal ultrasound
(A) 0
(B) $1-5 \mathrm{X}$
(C) 5-10X
(D) $10-50 \mathrm{X}$
(E) $50-300 \mathrm{X}$
(F) Greater than 300X
(G) DN

(11) Bone scan
(A) 0
(B) $1-5 \mathrm{X}$
(C) $5-10 \mathrm{X}$
(D) $10-50 \mathrm{X}$
(E) $50-300 \mathrm{X}$
(F) Greater than 300X
(G) DN

(12) Barium meal
(A) 0
(B) $1-5 \mathrm{X}$
(C) $5-10 \mathrm{X}$
(D) $10-50 \mathrm{X}$
(E) $50-300 \mathrm{X}$
(F) Greater than 300X
(G) DN

(13) Spiral CT of abdomen
(A) 0
(B) $1-5 \mathrm{X}$
(C) $5-10 \mathrm{X}$
(D) $10-50 \mathrm{X}$
(E) $50-300 \mathrm{X}$
(F) Greater than 300X
(G) DN

(14) Spine MRI
(A) 0
(B) $1-5 \mathrm{X}$
(C) 5-10X
(D) $10-50 \mathrm{X}$
(E) 50-300X
(F) Greater than 300X
(G) DN 
(15) PET scan
(A) 0
(B) $1-5 \mathrm{X}$
(C) $5-10 X$
(D) $10-50 X$
(E) $50-300 \mathrm{X}$
(F) Greater than 300X
(G) $\mathrm{DN}$

Please rate the following organs in terms of their sensitivity to ionizing radiation.

(16) Ovary/Testes
(A) Very insensitive
(B) Moderately insensitive
(C) Moderately sensitive
(D) Very sensitive
(E) $\mathrm{DN}$

(17) Breast
(A) Very insensitive
(B) Moderately insensitive
(C) Moderately sensitive
(D) Very sensitive
(E) $\mathrm{DN}$

(18) Skin/Cortical Bone
(A) Very insensitive
(B) Moderately insensitive
(C) Moderately sensitive
(D) Very sensitive
(E) $\mathrm{DN}$

(19) Lung/Colon
(A) Very insensitive
(B) Moderately insensitive
(C) Moderately sensitive
(D) Very sensitive
(E) $\mathrm{DN}$

(20) Liver/Kidney/Bladder
(A) Very insensitive
(B) Moderately insensitive
(C) Moderately sensitive
(D) Very sensitive
(E) $\mathrm{DN}$

(21) What is the risk of inducing fatal cancer from an abdominal CT scan?

(A) 1 in 200
(B) 1 in 2000
(C) 1 in 20,000
(D) 1 in 200,000
(E) $\mathrm{DN}$

(22) Have you ever had education in the form of lectures, tutorials, or courses regarding ionizing radiation?
(A) Lectures
(B) Tutorials/workshops
(C) A combination of the above two
(D) None

(23) If you were to have a choice, which of the following kinds of education do you think would help you the most to raise awareness of ionizing radiation? (Select only one)
(A) Lectures
(B) Tutorials or workshops
(C) Case studies
(D) Learning modules

\section{Conflict of Interests}

The authors declare that there is no conflict of interests regarding the publication of this paper.

\section{References}

[1] J. J. Stein, "The carcinogenic hazards of ionizing radiation in diagnostic and therapeutic radiology," Ca: A Cancer Journal for Clinicians, vol. 17, no. 6, pp. 278-287, 1967.

[2] P. Scanff, J. Donadieu, P. Pirard, and B. Aubert, "Population exposure to ionizing radiation from medical examinations in France," The British Journal of Radiology, vol. 81, no. 963, pp. 204-213, 2008.

[3] D. J. Brenner, "Fractionation and late rectal toxicity," International Journal of Radiation Oncology Biology Physics, vol. 60, no. 4, pp. 1013-1015, 2004.

[4] J. X. Wang, L. A. Zhang, B. X. Li et al., "Cancer incidence and risk estimation among medical X-ray workers in China, 19501995," Health Physics, vol. 82, no. 4, pp. 455-466, 2002.

[5] Z. Goldberg, C. W. Schwietert, B. Lehnert, R. Stern, and I. Nami, "Effects of low-dose ionizing radiation on gene expression in human skin biopsies," International Journal of Radiation Oncology Biology Physics, vol. 58, no. 2, pp. 567-574, 2004.

[6] A. Arslanoglu, S. Bilgin, Z. Kubali, M. N. Ceyhan, M. N. Ilhan, and I. Maral, "Doctors' and intern doctors' knowledge about patients' ionizing radiation exposure doses during common radiological examinations," Diagnostic and Interventional Radiology, vol. 13, no. 2, pp. 53-55, 2007.

[7] I. Børretzen, K. B. Lysdahl, and H. M. Olerud, "Diagnostic radiology in Norway: trends in examination frequency and collective effective dose," Radiation Protection Dosimetry, vol. 124, no. 4, pp. 339-347, 2007.

[8] D. J. Brenner, C. D. Elliston, E. J. Hall, and W. E. Berdon, "Estimated risks of radiation-induced fatal cancer from pediatric CT," The American Journal of Roentgenology, vol. 176, no. 2, pp. 289-296, 2001. 
[9] P. C. Shrimpton and S. Edyvean, "CT scanner dosimetry," British Journal of Radiology, vol. 71, no. 841, pp. 1-3, 1998.

[10] F. A. Mettler Jr., P. W. Wiest, J. A. Locken, and C. A. Kelsey, "CT scanning: patterns of use and dose," Journal of Radiological Protection, vol. 20, no. 4, pp. 353-359, 2000.

[11] A. Paterson, D. P. Frush, and L. F. Donnelly, "Helical CT of the body: are settings adjusted for pediatric patients?" The American Journal of Roentgenology, vol. 176, no. 2, pp. 289-296, 2001.

[12] C. Hollingsworth, D. P. Frush, M. Cross, and J. Lucaya, "Helical CT of the body: a survey of techniques used for pediatric patients," American Journal of Roentgenology, vol. 180, no. 2, pp. 401-406, 2003.

[13] S. Shiralkar, A. Rennie, M. Snow, R. B. Galland, M. H. Lewis, and K. Gower-Thomas, "Doctors' knowledge of radiation exposure: questionnaire study," British Medical Journal, vol. 327, no. 7411, pp. 371-372, 2003.

[14] H. E. Rice, D. P. Frush, M. J. Harker, D. Farmer, and J. H. Waldhausen, "Peer assessment of pediatric surgeons for potential risks of radiation exposure from computed tomography scans," Journal of Pediatric Surgery, vol. 42, no. 7, pp. 1157-1164, 2007.

[15] A. D. Quinn, C. G. Taylor, T. Sabharwal, and T. Sikdar, "Radiation protection awareness in non-radiologists," British Journal of Radiology, vol. 70, pp. 102-106, 1997.

[16] K. Jacob, G. Vivian, and J. R. Steel, "X-ray dose training: are we exposed to enough?” Clinical Radiology, vol. 59, no. 10, pp. 928934, 2004.

[17] C. I. Lee, A. H. Haims, E. P. Monico, J. A. Brink, and H. P. Forman, "Diagnostic CT scans: assessment of patient, physician, and radiologist awareness of radiation dose and possible risks," Radiology, vol. 231, no. 2, pp. 393-398, 2004.

[18] K. E. Thomas, J. E. Parnell-Parmley, S. Haidar et al., "Assessment of radiation dose awareness among pediatricians," Pediatric Radiology, vol. 36, no. 8, pp. 823-832, 2006.

[19] C. M. Heyer, S. Peters, S. Lemburg, and V. Nicolas, "Awareness of radiation exposure of thoracic CT scans and conventional radiographs: what do non-radiologists know?" Fortschr Röntgenstr, vol. 179, no. 3, pp. 261-267, 2007.

[20] J. A. Soye and A. Paterson, "A survey of awareness of radiation dose among health professionals in Northern Ireland," British Journal of Radiology, vol. 81, no. 969, pp. 725-729, 2008.

[21] M. Seyed, A. Qamar, and N. Nighat, "Knowledge about ionizing and non-ionizing radiation among medical students," Journal of Ayub Medical College Abbottabad, vol. 20, no. 1, pp. 118-121, 2008.

[22] G. Z. Zhou, D. D. Wong, L. K. Nguyen, and R. M. Mendelson, "Student and intern awareness of ionising radiation exposure from common diagnostic imaging procedures," Journal of Medical Imaging and Radiation Oncology, vol. 54, no. 1, pp. 1723, 2010.

[23] G. B. Keijzers and C. J. Britton, "Doctors' knowledge of patient radiation exposure from diagnostic imaging requested in the emergency department," Medical Journal of Australia, vol. 193, no. 8, pp. 450-453, 2010.

[24] Z. Daniel, T. Seife, and A. Tewodros, "A study of knowledge \& awareness of medical doctors towards radiation exposure risk at Tikur Anbessa specialized referral and teaching hospital, Addis Ababa, Ethiopia," IOSR Journal of Pharmacy and Biological Sciences, vol. 2, no. 4, pp. 1-5, 2012. 


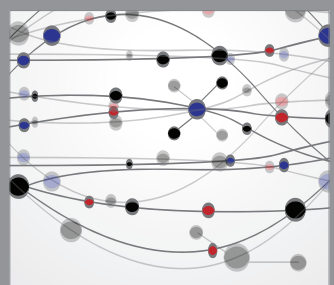

The Scientific World Journal
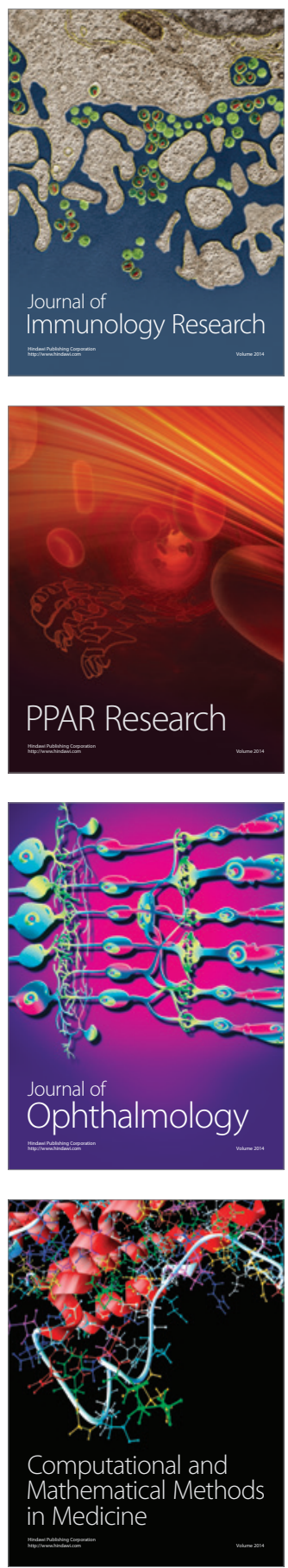

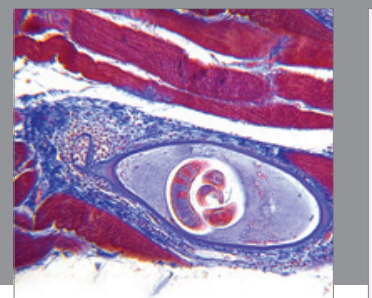

Gastroenterology

Research and Practice
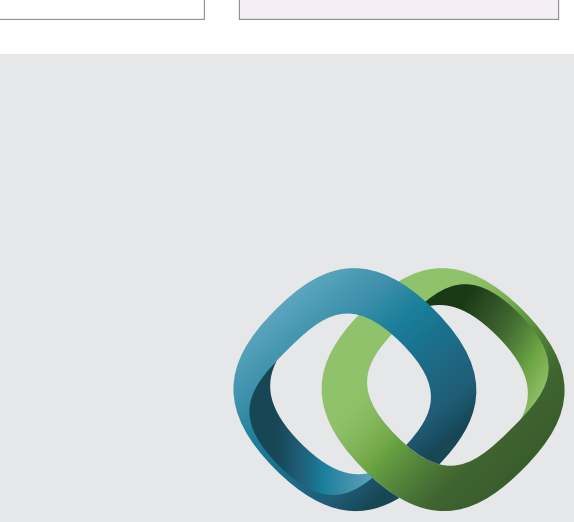

\section{Hindawi}

Submit your manuscripts at

http://www.hindawi.com
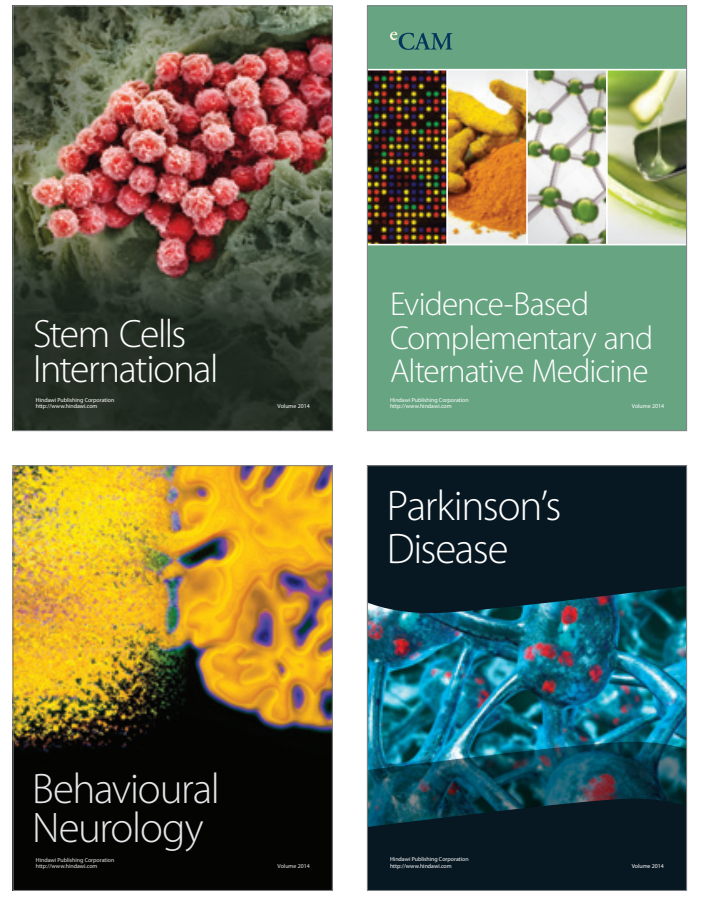
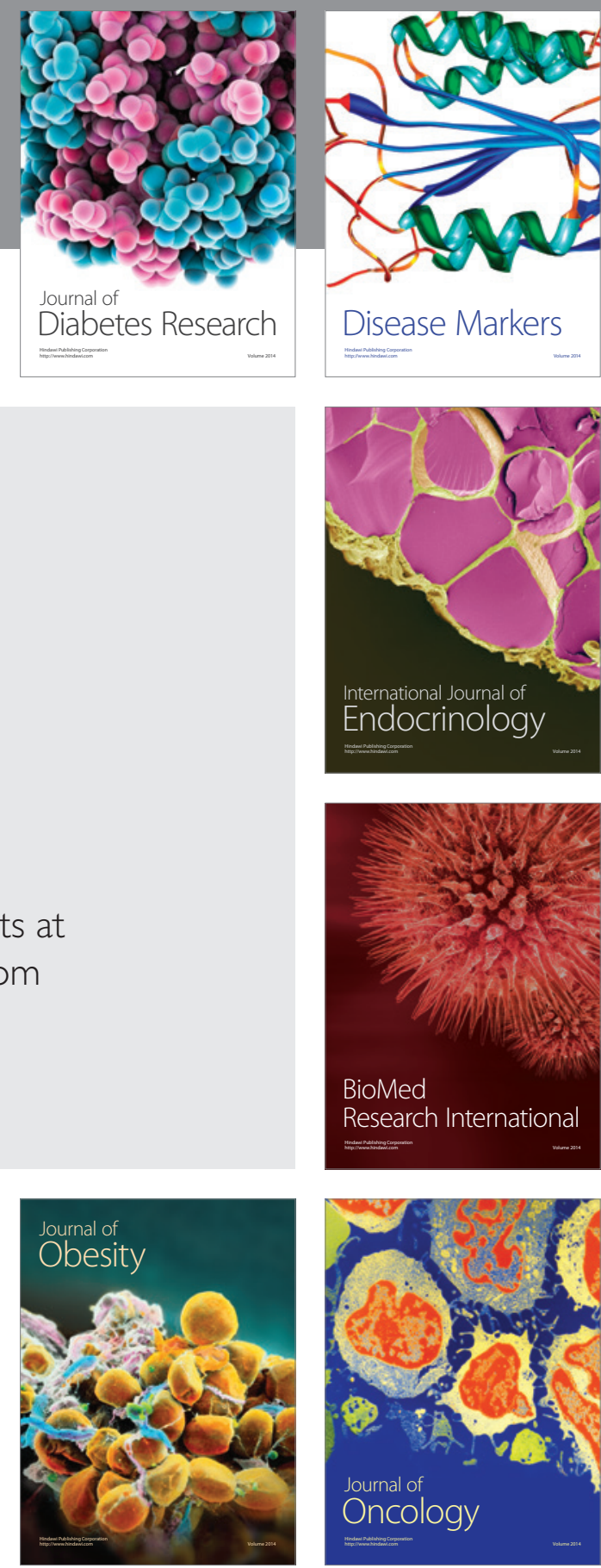

Disease Markers
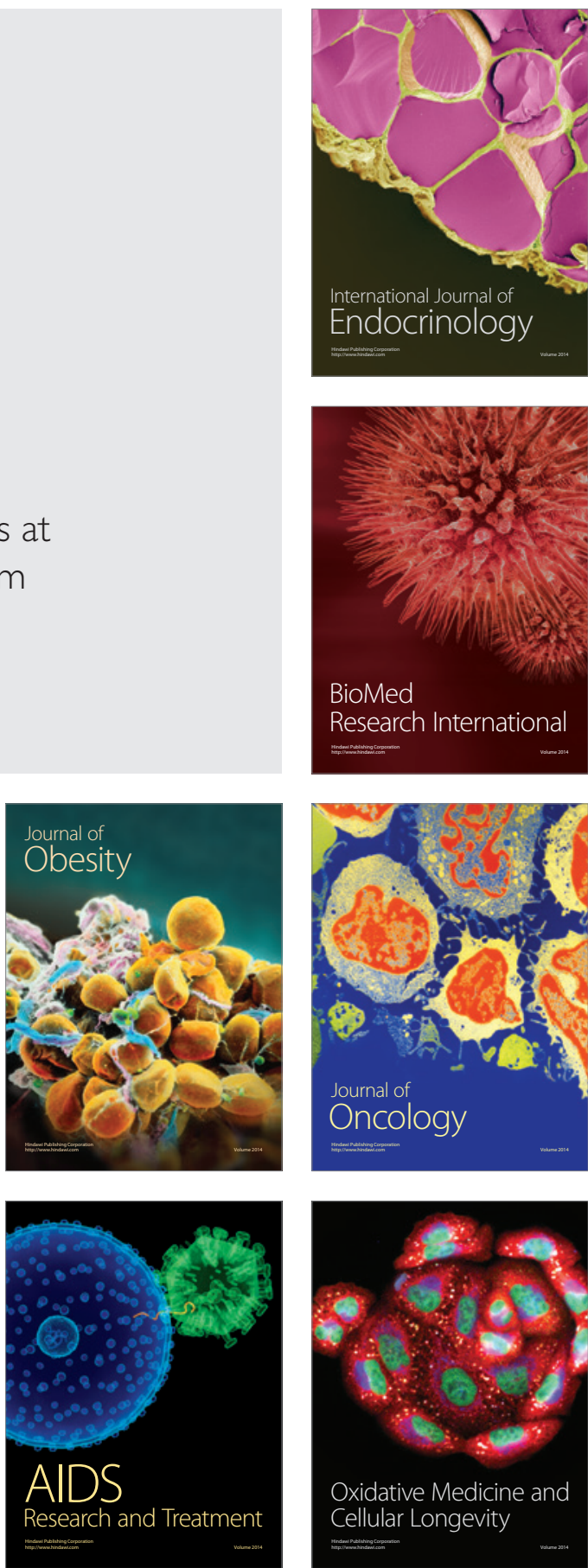